\title{
Retraso y velocidades de lectura en la subtitulación para personas sordas de los informativos
}

\author{
Julio de los Reyes Lozano | Laura Mejías-Climent | José Luis Martí Ferriol \\ Universitat Jaume I \\ delosrey@uji.es | Imejias@uji.es | martij@uji.es
}

Recibido: 15/01/2020 | Revisado: 16/06/2020 | Aceptado: 21/07/2020

\section{Resumen}

Este artículo surge de ITACA (Inclusión social, Traducción Audiovisual y Comunicación Audiovisual ${ }^{1}$ ), un proyecto de investigación interuniversitario e interdisciplinar sobre producción audiovisual accesible que pretende mejorar el acceso de las personas con limitaciones sensoriales a los medios audiovisuales. El estudio descriptivo que aquí presentamos se centra en la subtitulación para sordos (SPS) de los informativos, que suele elaborarse en directo o semidirecto. A tal fin, se seleccionaron once fragmentos de noticiarios emitidos en distintas cadenas públicas y privadas de televisión españolas. El retraso y la velocidad de lectura de los subtítulos, dos de los parámetros habituales para el análisis de la SPS, son la base de las hipótesis de trabajo y del marco analítico, cuyo objetivo es evaluar la SPS de los informativos desde una doble perspectiva, traductológica y fílmica. En líneas generales, los resultados muestran mayor retraso y menor velocidad de lectura en los subtítulos en directo respecto de los emitidos en semidirecto, lo que puede influir en la recepción por parte de los destinatarios finales.

Palabras clave: SPS, subtitulación en directo, accesibilidad, velocidad de lectura, informativos

\section{Abstract \\ Delay and Reading Speed in Subtitling for the Deaf and Hard-of-Hearing of TV News Programmes}

The framework for this article is the research project ITACA (Social Inclusion, Audiovisual Translation and Audiovisual Communication), an inter-university and interdisciplinary project on accessible filmmaking whose aim is to improve accessibility to audiovisual media for people with sensory limitations. The descriptive study presented here focuses on the subtitling for the deaf and hard-of-hearing (SDH) of TV news programmes (live and semi-live or as-live subtitling). For the analysis, eleven clips of TV news programmes broadcasted on different public and private Spanish television channels were selected. Delay and reading speed being two of the common parameters of SDH analysis, they were chosen as the basis of the hypotheses and the analytical framework, aimed at evaluating SDH from both translational and filmic point of view. The results show a greater delay and a lower reading speed in live than in semi-live subtitles, which may have an impact on the reception by the final viewers. 


\section{El proyecto ITACA}

La subtitulación para personas sordas y con deficiencias auditivas (SPS) es una de las modalidades de Traducción Audiovisual (TAV) accesibles contempladas dentro del proyecto de investigación ITACA (Inclusión social, Traducción Audiovisual y Comunicación Audiovisual). El objetivo principal de este proyecto interuniversitario e interdisciplinar es mejorar el nivel de accesibilidad de los productos audiovisuales para personas con capacidades sensoriales limitadas, como es el caso de la sordera, en el que nos centraremos en estas páginas, destinadas a presentar el planteamiento y la metodología de un estudio descriptivo llevado a cabo sobre once fragmentos de informativos con subtítulos en directo y semidirecto. Este análisis representa la fase previa a un estudio de recepción posterior del que podrán derivar propuestas de mejora de la subtitulación en directo y semidirecto, según la percepción y las preferencias que expresen los usuarios de esta modalidad de TAV accesible.

Además del estudio descriptivo objeto de este artículo, centrado en la modalidad de SPS, el proyecto ITACA en su conjunto gira en torno al concepto de producción audiovisual accesible o Accesible Filmmaking (Romero-Fresco, 2013). Se trata de integrar la accesibilidad en el mismo proceso de creación y producción audiovisual, de forma que se contemplen, desde el inicio del desarrollo del producto, las garantías necesarias para asegurar su posterior consumo accesible y de calidad, considerando una serie de factores tanto semióticos como lingüísticos y de producción audiovisual. Con los resultados del proyecto, se pretende ofrecer a medio plazo asesoramiento sobre traducción y accesibilidad a los realizadores de productos audiovisuales, así como una guía de buenas prácticas para la elaboración de vídeos accesibles, una base de datos sobre producción audiovisual accesible y un vídeo explicativo elaborado según el mismo concepto de producción audiovisual accesible.

El proyecto ITACA se fundamenta en la estrecha colaboración entre productores audiovisuales (expertos audiovisuales y creadores de contenido, del ámbito de la Comunicación Audiovisual), traductores audiovisuales y expertos en accesibilidad del campo de la TAV, lo que garantiza su carácter interdisciplinar e integrador. Tras la correspondiente preparación y revisión bibliográfica y el estudio de las convenciones de las dos principales modalidades de TAV accesibles (audiodescripción para personas ciegas y con discapacidad visual y SPS), se dio paso a una fase de estudio descriptivo de los productos en directo. Para ello, se seleccionó el corpus de trabajo a partir de un catálogo de informativos, un producto audiovisual escasamente tratado en investigaciones previas sobre accesibilidad. A continuación, se analizó el corpus desde un doble enfoque, traductológico y fílmico, atendiendo a la SPS y a las necesidades de las personas ciegas o con problemas de visión. En la última fase del proyecto, se han llevado a cabo dos estudios de recepción: uno referido a la ceguera y otro sobre personas sordas y con limitaciones auditivas.

En lo que concierne a la SPS, con el estudio descriptivo como punto de partida se han identificado algunas de las necesidades específicas que podrían manifestar las 
personas con problemas auditivos y las carencias que estos usuarios podrían detectar en el citado género audiovisual de los informativos. Estas necesidades de mejora se comprobarán con el posterior estudio de recepción, elaborado y llevado a cabo a partir de los resultados que presentamos a continuación. En suma, la intención es detectar y confirmar carencias, así como proponer medidas de mejora mediante una producción audiovisual accesible, es decir, integrando la accesibilidad en las fases de preproducción, producción y postproducción de los informativos.

\section{La SPS como modalidad de TAV accesible}

La subtitulación para personas sordas y con deficiencias auditivas (SPS) consiste en la adición de texto en pantalla, generalmente en la misma lengua que el producto original (aunque también puede ser interlingüística), en el que se da cuenta no solamente de los diálogos, como es el caso de la subtitulación convencional, sino también de toda aquella información transmitida por el canal acústico que una persona con deficiencias auditivas podría no percibir completa: identificación de personajes (por colores, etiquetas o guiones), información contextual (entonación, estado de ánimo, volumen, acentos o emociones implicados en los diálogos), los efectos sonoros (cualquier ruido o sonido necesario para la trama) y la música o las canciones.

Desde su aparición en televisión en la década de los 70 (Ivarsson y Carroll, 1998: 24), esta modalidad de TAV ha evolucionado visiblemente en función de los avances tecnológicos y mediáticos (para una revisión de la historia de la SPS, véase Díaz-Cintas, 2010 y Tamayo, 2015). Inicialmente, la investigación en el ámbito de la accesibilidad no parecía encajar entre las disciplinas académicas tradicionales, siendo este uno de los motivos por los que los estudios en SPS y audiodescripción eran muy escasos en sus orígenes (Díaz-Cintas, 2010: 59). Sin embargo, en especial en los últimos años, han sido numerosos los estudios que le han prestado mayor atención (Romero-Fresco, 2015; Zárate y Eliahoo, 2014; Romero-Fresco, 2013; Matamala y Orero, 2010; Neves, 2008; Matamala y Orero, 2008; Orero, Pereira y Utray, 2007, por citar solo algunos). Este impulso investigador se ha visto motivado, principalmente, por los citados avances tecnológicos, la diversificación del consumo audiovisual y las plataformas de vídeo bajo demanda, así como la implantación de leyes y normativas en favor de una producción audiovisual accesible (Neves, 2018), como es el caso de la Ley General de la Comunicación Audiovisual de 2010 de nuestro país, que establece los porcentajes de emisión accesible que las cadenas, tanto públicas como comerciales, deben poner a disposición de la audiencia, y el posterior Real Decreto Legislativo 1/2013, de 29 de noviembre, por el que se aprueba el Texto Refundido de la Ley General de derechos de las personas con discapacidad y de su inclusión social.

Como ya sucedía desde hace algunos años en países pioneros como el Reino Unido, Estados Unidos, Canadá, Australia, Francia o Dinamarca (Neves, 2018: 84), que prácticamente alcanzan el $100 \%$ de subtitulado para las emisiones en cadenas públicas, en España, las cadenas públicas parecen cumplir con el requisito de emitir, ya en 
2017, el 90 \% de las emisiones televisivas con SPS (CNMC, 2019: 12). Sin embargo, dadas las imposiciones legales de llegar a estas cuotas de accesibilidad, parece que la prioridad se ha centrado, inicialmente, en acercar la accesibilidad a las audiencias; a continuación, en alcanzar los porcentajes requeridos por ley y, solo entonces, en mejorar la calidad de ese servicio accesible. Es en este último aspecto en el que se pretende incidir con el estudio presentado en estas páginas, como punto de partida para el posterior estudio de recepción, en función de ciertos parámetros de la SPS que expondremos a continuación.

Dada la dificultad de establecer en qué consiste una subtitulación de calidad (Neves, 2018), este estudio parte de investigaciones previas sobre SPS (Romero-Fresco y Martínez, 2015; AENOR, 2012; Romero-Fresco, 2011) para centrarse en dos aspectos fundamentales del subtitulado: la velocidad de lectura o exposición y el retraso (conocido como tal por buena parte de la bibliografía citada, pero también denominado retardo por la norma UNE 153010, a la que se hará referencia a continuación). La efectividad de la SPS, según expone Neves (2018: 91), está estrechamente relacionada con tres aspectos esenciales: la legibilidad de los subtítulos, su comprensión y su disfrute. En consecuencia, para determinar, en especial, los dos primeros, debe hablarse de parámetros como la velocidad de lectura y el retraso que la subtitulación en directo y semidirecto pueda presentar.

La publicación en 2003 de la norma UNE 153010, elaborada por la Asociación Española de Normalización y Certificación (AENOR), supuso uno de los principales avances en favor de la homogeneización de unos criterios de calidad mínimos para la SPS en nuestro país. Esta norma fue sustituida casi una década después por la actual UNE 153010:2012 de Subtitulado para personas sordas y personas con discapacidad auditiva. En ella se considera la velocidad de lectura o velocidad de exposición de los subtítulos como el número de caracteres por segundo (CPS) que se muestran en pantalla. En España, la recomendación se establece en un máximo de $15 \mathrm{CPS}$, de forma que «la velocidad de exposición del texto del subtítulo [siga] el ritmo del original y [facilite] una lectura cómoda» (AENOR, 2012: 10). Se trata de un «parámetro fundamental de calidad en subtitulación, que se obtiene como cociente entre la cantidad de caracteres que componen el subtítulo y la duración del mismo; es decir, la diferencia entre el tiempo de salida y el tiempo de entrada» (Martí Ferriol, 2019: 136).

En el caso de nuestro corpus, trabajamos con el género televisivo de los informativos. Al tratarse de programas de producción propia, la SPS que se emplea es intralingüística, en español. Estos subtítulos se emiten en directo o semidirecto, es decir, se trata de «subtitulado de programas en directo o programas grabados que no estaban disponibles con la antelación suficiente para preparar los subtítulos antes de su emisión» (AENOR, 2012: 7). Del mismo modo, el subtitulado en semidirecto será aquel «producido antes de que se emita un programa, pero sincronizado durante su emisión» (id.).

La subtitulación en directo y semidirecto, según la misma norma UNE de 2012, representa una excepción en el sincronismo o sincronía que siempre se requiere en 
todo subtítulo con respecto a los diálogos emitidos en pantalla y a la configuración audiovisual del producto. Esta sincronía contribuye a una mejor comprensión para la audiencia, en especial, para aquellos «que complementan la lectura de subtítulos con la audición» y en subtítulos intralingüísticos, dado que «permite apoyarse en el sincronismo labial-auditivo, evitando confusiones» (id.). Sin embargo, en la SPS elaborada en directo o semidirecto, la norma UNE contempla un posible retraso de hasta 8 segundos, dadas las posibilidades tecnológicas de las que se dispone hasta ahora.

Para la producción de los subtítulos en directo, se suele emplear la técnica de rehablado, que consiste en repetir literalmente las locuciones emitidas en pantalla frente a un software de reconocimiento de voz para que este las vaya convirtiendo en el texto escrito de los subtítulos (Romero-Fresco, 2018: 96). Con el rehablado, se pretende conseguir el menor tiempo de retraso posible, aunque la velocidad de las locuciones orales televisivas y las limitaciones del software pueden dificultar en gran medida esta práctica. En el apartado de resultados, se comprobará el nivel de retraso y la velocidad de lectura de la SPS en las emisiones actuales de informativos en el panorama audiovisual español.

\section{Los informativos en la televisión: características y accesibilidad}

Como se ha adelantado, el análisis de los anteriores parámetros de la SPS se ha llevado a cabo sobre un corpus compuesto por informativos televisados. En tanto que género audiovisual, el informativo, telediario o noticiario refleja la inmediatez de cualquier noticia y tiene su razón de ser en las expectativas de la audiencia por conocer la verdad de lo sucedido; se trata de «describir un hecho noticioso» (Marín, 2017). Representa un formato televisivo fundamentado en la noticia que tiene asegurada su presencia en la parrilla de televisión (id.), tanto los diarios como los no diarios. Los primeros han sido el tipo de telediario analizado, es decir, aquellos emitidos de lunes a viernes y fines de semana por la mañana, al mediodía y por la noche. Son parte fundamental de todas las cadenas generalistas españolas y representan la principal fuente de información diaria para alrededor del $50 \%$ de la población española (id.; Díaz Arias, 2011: 66). De ello se desprende la importancia de la accesibilidad en este tipo de formato televisivo, para garantizar el acceso universal a la información, sean cuales sean las condiciones sensoriales de los telespectadores.

En cuanto a su formato, los informativos actuales están segmentados en piezas con bloques temáticos diferenciados por separadores. El discurso lo estructura el presentador en el plató y las imágenes de los hechos complementan el mensaje verbal narrado. Los reporteros ofrecen entrevistas y narraciones desde el lugar de los hechos y el sonido ambiente conlleva capacidad expresiva. Además, se emplea grafismo identificativo para las personas y lugares (Casado Ruiz, 2011: 105). Toda esta configuración audiovisual debería determinar los aspectos básicos que deben cubrir los subtítulos para sordos, cuya función es suplir la carencia acústica, en mayor o menor medida, de 
los telespectadores con cualquier grado de sordera. De ahí la importancia de plantear un estudio descriptivo global, con una doble vertiente: además del enfoque traductológico, también un análisis fílmico.

En un informativo pueden encontrarse distintos géneros (Marín, 2017): la cabecera, la noticia, la crónica, el reportaje, el directo, el falso directo y los créditos. Asimismo, existen diversos formatos incluidos en el telediario: la pieza, el editado o pieza sin totales, la cola o apoyo, el total o batería de totales, los breves, la encuesta, el clip, el sumario, el cebo, el background y los brutos. Estos elementos de un informativo, así como las partes de una pieza, la técnica narrativa empleada, los movimientos de cámara y los elementos de puntuación audiovisuales, entre otros aspectos, serán objeto de catalogación en el análisis fílmico por parte de los expertos en Comunicación Audiovisual de ITACA, de forma que el estudio de cada subtítulo se integre en la configuración audiovisual completa del momento en el que aparece en el informativo.

\section{Metodología y corpus}

\subsection{Objetivo e hipótesis de trabajo}

Tras la revisión teórica de los conceptos relacionados con la SPS y los informativos, hemos llevado a cabo el análisis basándonos en las convenciones básicas de la SPS formuladas en AENOR (2012), así como en estudios previos sobre la SPS en directo (Romero-Fresco y Martínez, 2015; Romero-Fresco, 2011) que reflejan mayores diferencias entre subtítulos en los dos siguientes aspectos:

- La asincronía de los subtítulos en los informativos. Habitualmente, los subtítulos en directo se retrasan respecto a los subtítulos en semidirecto y, al mismo tiempo, estos suelen aparecer con retraso también en las transiciones entre intervenciones en directo y formatos preparados con antelación en la escaleta.

- La velocidad de exposición de los subtítulos. Por lo general, los subtítulos en semidirecto son mucho más precisos en cuanto a errores de edición, pero presentan una velocidad de exposición mucho mayor. Por el contrario, debido a la velocidad de locución de las caras visibles de los informativos, los subtítulos en directo por rehablado suelen estar más editados (se omite o se reformula información) y, por consiguiente, presentan una velocidad de exposición menor, al tiempo que un mayor índice de errores de edición.

El objetivo principal del análisis descriptivo en su vertiente traductológica es, por tanto, analizar los subtítulos para personas sordas emitidos en las distintas piezas de los informativos con el fin de evaluar el retraso y la velocidad de lectura. Para ello, se formulan las siguientes hipótesis: 
- Se detectará una mayor diferencia entre el inicio de las intervenciones y los subtítulos que las reproducen (probablemente un retraso) en los subtítulos en directo que en los emitidos en semidirecto.

- Se detectará una mayor velocidad de lectura en los subtítulos emitidos en semidirecto que en los subtítulos en directo.

De forma transversal, desde un punto de vista fílmico, nos proponemos observar el grado de sincronía y la relevancia de la información audiovisual.

\subsection{Modelo de análisis}

Como se ha avanzado, el marco analítico se desdobla en traductológico y fílmico, con el fin de abordar el estudio de la SPS de forma holística. En primer lugar, el análisis traductológico se centra en el cálculo del posible retraso en la aparición de los subtítulos, así como en su velocidad de exposición. Para ello, se elaboró una ficha de análisis en una hoja de cálculo (ver Imagen 1) en la que se incluye la siguiente información para cada muestra:

- Referencia de la muestra: numeración correlativa de cada muestra.

- Referencia del fragmento: especificación de la pieza del informativo del que procede la muestra.

- Referencia del corpus: especificación del informativo del que procede la muestra.

- Transcripción de las intervenciones: transcripción literal de las intervenciones que se escuchan en la muestra.

- Copia del subtítulo: copia del subtítulo extraído con el programa de subtitulación Subtitle Edit, previa extracción en formato .srt. Como este proceso es semiautomático, se confirma que el subtítulo del archivo coincide exactamente con el reproducido en pantalla.

- TCR inicial de las intervenciones: tiempos de entrada de la transcripción en formato hh:mm:ss, extraídos del reproductor de vídeo VLC Player.

- TCR inicial del subtítulo: tiempos de entrada del subtítulo en formato hh:mm:ss, extraídos del archivo de subtítulos y eliminando los milisegundos.

- Diferencia de tiempo: cálculo automático de la diferencia entre el tiempo de entrada del subtítulo y el tiempo de entrada de la transcripción mediante una fórmula incluida en la hoja de cálculo. Esta celda incluye un formato de color condicional: si la celda está vacía, sale por defecto 0 (verde), lo que significa que no hay retraso; si la cifra es negativa, se marca la celda en cian y significa que el subtítulo se adelanta; si es positiva, se marca la celda en rojo y significa que el subtítulo se atrasa.

- Velocidad del subtítulo en CPS: calculada con la herramienta Black Box ${ }^{2}$ a partir del archivo .srt creado con Subtitle Edit. 


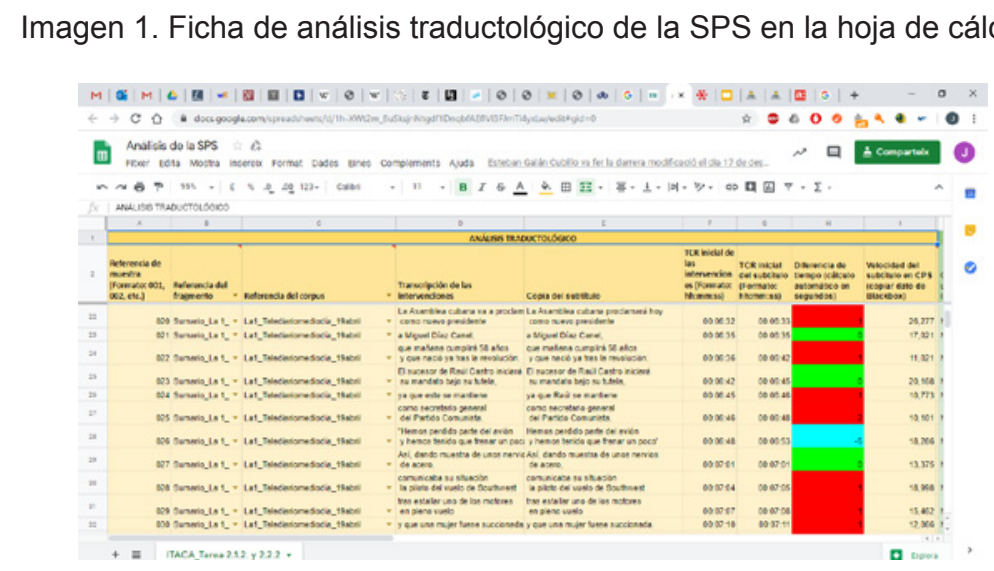

En relación con el análisis fílmico, el interés se centró en concreto en saber si la información audiovisual es reiterativa o complementaria y si los códigos gráficos y sonoros están en sincronía. De forma adicional, los expertos en Comunicación Audiovisual del equipo analizaron otros aspectos complementarios, tales como la técnica narrativa, los movimientos de cámara o la planificación utilizada. A tal fin, se incorporó una ficha de análisis (ver Imagen 2) en la misma hoja de cálculo en la que se incluye esta información para cada muestra:

- Género de un informativo: se distingue entre cabecera, noticia, crónica, reportaje, directo, falso directo y créditos.

- Formato de noticia: se distingue entre pieza, vídeo o VTR (video tape recorder); editado o pieza sin totales; cola o apoyo; total o batería de totales; breves; encuesta; clip; sumario; cebo; background y brutos.

- Partes de una pieza: puede ser entradilla, cuerpo, total, entradilla a cámara, medianilla, salidilla y N/A (no aplica).

- Técnica narrativa: puede tratarse de encabalgado de audio, flashback, fuera de campo, montaje paralelo o alterno, plano recurso, rótulo, sonido ambiente, total, voz en off y N/A (no aplica).

- Movimientos de cámara: se distingue entre panorámica, travelling, grúa, cámara al hombro, plano estático y N/A (no aplica).

- Elementos de puntuación: hablamos de cambio de plano por fundido (a un color), encadenado (entre dos planos), corte, cortinilla, efectos, catch y N/A (no aplica).

- Plano: se distingue entre PPP (primerísimo primer plano), PP (primer plano), PM (plano medio), PML (plano medio largo); PA (plano americano), PC (plano conjunto), PG (plano general), GPG (gran plano general) y N/A (no aplica).

- Cara visible del informativo: puede ser presentador/a, corresponsal, redactor/a, reportero/a y testimonio.

- Sincronía: se analiza si existe sincronía entre la imagen y la intervención y se elige entre «Sí» y «No».

- Análisis de la información: se estudia si la información de la pieza se ofrece por duplicado (enfoque reiterativo) o si los distintos elementos de la obra audiovisual se complementan (enfoque complementario). 
Imagen 2. Ficha de análisis fílmico de la SPS en la hoja de cálculo

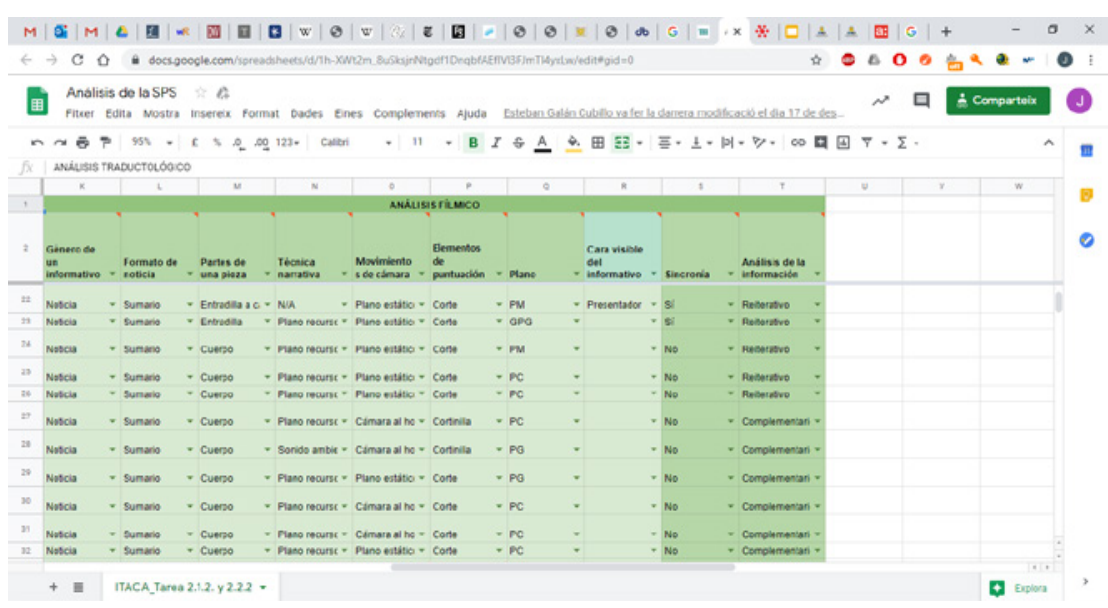

\subsection{Selección y análisis del corpus}

Como ya hemos avanzado, el corpus de trabajo lo conforman varios fragmentos de diferentes programas informativos emitidos en televisiones españolas durante 2018. La elección de los informativos como objeto de análisis se debe a que, además de desempeñar un papel esencial en la difusión de la información, estos representan un formato televisivo consolidado que maneja datos de audiencia considerables y que, sin embargo, no suele tener en cuenta su accesibilidad. Asimismo, en España los subtítulos para sordos de este tipo de programas suelen emitirse en directo o semidirecto, lo cual, con mucha frecuencia, genera problemas de retraso y velocidad de lectura que pueden influir en gran medida en la recepción por parte del destinatario.

Siguiendo la metodología del grupo TRACE (Gutiérrez Lanza, 2007), el catálogo o corpus 0 se redujo a una semana. Para compilarlo, durante la semana del 16 al 22 de abril de 2018 se grabaron todos los programas informativos emitidos por los tres grandes canales de las corporaciones televisivas más representativas en España: Mediaset, Atresmedia y RTVE. Para ello, se utilizó el programa VLC Player y un disco duro multimedia. Estas grabaciones fueron, a continuación, catalogadas y categorizadas por los expertos en comunicación del equipo, quienes se encargaron de seleccionar las piezas representativas de los distintos programas informativos y que después se analizarían, siguiendo un enfoque traductológico y fílmico.

En este punto, es importante subrayar que no se analizaron las grabaciones completas, sino únicamente las piezas seleccionadas previamente por los expertos en Comunicación Audiovisual del equipo ITACA en función de su representatividad y características. Asimismo, algunos programas fueron descartados, debido a que el software no permitía extraer los archivos de subtítulos. Por último, se decidió no analizar los deportes y la meteorología, por considerarse que se trata de espacios dentro de los informativos que siguen pautas similares a las de un magazín de entretenimiento, alejándose de la estructura de un informativo tradicional. 
Tras la aplicación de los distintos filtros se llegó al corpus de trabajo, compuesto por once fragmentos, que tiene la particularidad de ser coherente, homogéneo y representativo de los programas informativos televisados. En concreto, se analizaron los siguientes fragmentos:

- Sumario, La 1, 19 de abril

- Directo, A3, 22 de abril

- Pieza, vídeo o VTR (video tape recorder), La 1, 21 de abril

- Editado o pieza sin totales, A3, 19 de abril

- Cola o apoyo, A3, 22 de abril

- Total o batería de totales, La 1, 21 de abril

- Breves, La 1, 19 de abril

- Encuesta, A3, 19 de abril

- Clip/cierre, La 1, 19 de abril

- Cebo, A3, 19 de abril

- Background, A3, 22 de abril

\section{Resultados}

El análisis del corpus de trabajo arroja un total de 237 muestras recopiladas y completadas en su correspondiente hoja de cálculo, en la que se han podido llevar a cabo consultas por medio de la aplicación de filtros de selección de datos. Tras suprimir las muestras en las que no había SPS, bien por no aparecer en pantalla, bien por tratarse de subtítulos incrustados en el vídeo y no ser ejemplos de SPS, se obtuvo una hoja de cálculo de 229 filas que se ha usado como referencia para llevar a cabo todo el análisis, cuyos resultados se presentan en esta sección. En una publicación posterior se determinará si estos influyen en la identificación y comprensión del mensaje por parte de la audiencia, aspecto que se comprueba a través del correspondiente estudio de recepción diseñado y realizado en el marco del proyecto ITACA y cuyos resultados completarán próximamente este primer acercamiento descriptivo al corpus.

\subsection{Primera hipótesis}

De acuerdo con las conclusiones extraídas por Romero-Fresco (2009), las empresas de subtitulación que preparan subtítulos en directo emitidos en bloque se enfrentan a una restricción de tipo profesional, ya que los subtítulos se retrasan de 4 a 6 segundos simplemente por cuestiones técnicas. En consecuencia, en el proyecto ITACA se han considerado como retrasados aquellos subtítulos que presentan una diferencia de tiempo mayor de 5 segundos en relación con el inicio de la intervención subtitulada.

A este respecto, a partir de los datos recopilados en el análisis, se han obtenido los siguientes resultados generales: 
- Diferencia de tiempo > 5 segundos: 84 registros, de los cuales 22 son de subtítulos en semidirecto y 62 son de subtítulos en directo.

- Diferencia de tiempo > 10 segundos: 30 registros, de los cuales 9 son en semidirecto y 21 son en directo.

- La media aritmética de los retrasos de las muestras totales (directo y semidirecto) es de 4,54 segundos, con una desviación estándar de 0,71 .

Las dos primeras observaciones nos permiten corroborar la primera hipótesis, puesto que los retrasos se producen principalmente en los subtítulos en directo. En cuanto al valor medio de los retrasos, y siempre de acuerdo con Romero-Fresco (2009), este se podría considerar aceptable en términos generales si se consideran conjuntamente todos los subtítulos (semidirecto y directo).

Con objeto de comprobar si alguno de los elementos del análisis fílmico influye en las hipótesis y los resultados preliminares anteriores, se ha analizado la diferencia de tiempo filtrando, en primer lugar, por subtítulos en directo y en semidirecto y, en segundo lugar, por formato de noticia. Consideramos que estos dos análisis adicionales ayudan a particularizar con más detalle las dos conclusiones sobre las hipótesis generales, a la vez que aportan un mayor grado de profundidad en el análisis de los datos.

\subsubsection{Directo}

En la hoja de cálculo se registran 69 muestras de subtítulos realizados en directo procedentes de 4 fragmentos diferentes. De estas, 51 pertenecen al formato de «pieza» y 18 al de «encuesta». En la siguiente tabla se presentan los datos estadísticos del retraso de los subtítulos, de donde podemos deducir que el formato de noticia sí que tiene impacto en el retraso de los subtítulos en directo y que algunas piezas pueden tener más retraso que otras, como sucede en estos dos tipos. A simple vista, parece que el margen de mejora es superior en el formato de «pieza», al haber más subtítulos con retraso y, además, porque la media del retraso es superior, como se observa en los valores calculados de las medias.

Tabla 1. Retraso de los subtítulos en directo

\begin{tabular}{|c|c|c|c|}
\hline Formato de noticia & $\begin{array}{c}\text { Subtítulos retrasados }>5 \\
\text { segundos }\end{array}$ & $\begin{array}{c}\text { Subtítulos retrasados }>10 \\
\text { segundos }\end{array}$ & Media del retraso \\
\hline Pieza & 26 & 20 & 9,41 segundos \\
\hline Encuesta & 15 & 1 & 6,78 segundos \\
\hline
\end{tabular}

\subsubsection{Semidirecto}

En la hoja de cálculo se registran 158 muestras de subtítulos realizados en semidirecto procedentes de 7 fragmentos diferentes. De estas, 2 son ejemplos de «background», 23 de «breves», 16 de «cola», 4 de «encuesta», 49 de «pieza», 61 de «suma- 
rio» y 2 de «total». En la siguiente tabla se presentan los datos estadísticos del retraso de los subtítulos, donde se observa un mayor porcentaje de retraso en el formato de «cola» (8 registros de 16) y un mayor grado de sincronía en el «sumario» (19 registros de 61). Las categorías de «subtítulos adelantados» y «subtítulos sincrónicos» no se recogieron para el grupo anterior de subtítulos en directo, dada la imposibilidad de que se dé el adelanto de la subtitulación en un programa que se está realizando en directo, así como tampoco sería posible la sincronía absoluta por las limitaciones técnicas del rehablado.

Tabla 2. Retraso de los subtítulos en semidirecto

\begin{tabular}{|c|c|c|c|c|}
\hline Formato de noticia & $\begin{array}{c}\text { Subtítulos } \\
\text { adelantados }\end{array}$ & $\begin{array}{c}\text { Subtítulos } \\
\text { sincrónicos }\end{array}$ & $\begin{array}{c}\text { Subtítulos } \\
\text { retrasados }>5 \\
\text { segundos }\end{array}$ & $\begin{array}{c}\text { Subtítulos } \\
\text { retrasados }>10 \\
\text { segundos }\end{array}$ \\
\hline Background & 0 & 0 & 0 & 0 \\
\hline Breves & 4 & 1 & 0 & 0 \\
\hline Cola & 0 & 2 & 1 & 8 \\
\hline Encuesta & 1 & 0 & 6 & 0 \\
\hline Pieza & 0 & 19 & 5 & 0 \\
\hline Sumario & 0 & 0 & 0 & 1 \\
\hline Total & & 5 & & 0 \\
\hline
\end{tabular}

\subsection{Segunda hipótesis}

La media aritmética de los valores de velocidades de lectura expresados en CPS para todos los registros es de 17,33, por encima del valor máximo recomendado por la norma (15 CPS). Sin embargo, la desviación estándar para esta serie es muy elevada (6,43 CPS, más de un tercio del valor medio), lo que nos indica una gran variabilidad entre ellos. En concreto:

- CPS > 17: 120 registros, de los cuales 93 son en semidirecto y 27 en directo.

- CPS > 20: 82 registros, de los cuales 61 son en semidirecto y 21 en directo.

- CPS > 23: 47 registros, de los cuales 37 son en semidirecto y 10 en directo.

También hay algunos valores puntuales por encima de 30 (en concreto, 8 muestras). Con todo, para compensar estos valores tan elevados, se observa también una cantidad elevada de registros con velocidades bajas, ya que la media total es aceptable:

- CPS < 10: 46 registros, de los cuales 21 son en semidirecto y 25 en directo.

- CPS $<8$ (posibilidad de «relectura», según algunos estudios, Díaz Cintas y Remael, 2007): 26 registros, de los cuales 10 son en semidirecto y 16 en directo. 
No obstante, el reparto de dichos subtítulos de velocidades bajas es más uniforme entre subtítulos en semidirecto y subtítulos en directo. En cualquier caso, estas observaciones corroboran la segunda hipótesis de partida, ya que las velocidades de lectura son más elevadas en los subtítulos en semidirecto. Adicionalmente, al igual que para la primera hipótesis, se ha analizado la velocidad de lectura filtrando, en primer lugar, por subtítulos en directo y en semidirecto y, en segundo lugar, por formato de noticia.

\subsubsection{Directo}

Como hemos visto, en la hoja de cálculo 69 muestras de subtítulos realizados en directo procedentes de 4 fragmentos diferentes. De estas, 51 pertenecen al formato de «pieza» y 18 al de «encuesta». En relación con el primer formato, se han identificado los siguientes registros:

Tabla 3. Velocidades de lectura de los subtítulos en directo

\begin{tabular}{|c|c|c|c|c|c|}
\hline Formato de noticia & CPS $<8$ & CPS $<10$ & CPS $>17$ & CPS $>20$ & CPS $>23$ \\
\hline Pieza & 11 & 8 & 3 & 8 & 11 \\
\hline Encuesta & 5 & 1 & 3 & 3 & 1 \\
\hline
\end{tabular}

\subsubsection{Semidirecto}

Como hemos visto, en la hoja de cálculo se registran 158 muestras de subtítulos realizados en semidirecto procedentes de 7 fragmentos diferentes. De estas, 2 son ejemplos de «background», 23 de «breves», 16 de «cola», 4 de «encuesta», 49 de «pieza», 61 de «sumario» y 2 de «total».

Tabla 4. Velocidades de lectura de los subtítulos en semidirecto

\begin{tabular}{|c|c|c|c|c|c|c|}
\hline Formato de noticia & CPS $<8$ & CPS $<10$ & CPS $>17$ & CPS $>20$ & CPS $>23$ & CPS $>30$ \\
\hline Background & 2 & - & - & - & - & - \\
\hline Breves & 2 & 5 & 14 & 11 & 6 & 3 \\
\hline Cola & - & 1 & 10 & - & 8 & 3 \\
\hline Encuesta & 1 & 1 & 3 & 2 & - & 1 \\
\hline Pieza & 3 & 6 & 33 & 26 & 14 & 1 \\
\hline Sumario & 4 & 8 & 30 & 11 & 6 & - \\
\hline Total & - & - & - & - & - & \\
\hline
\end{tabular}


De estos datos se extraen las siguientes conclusiones preliminares:

- El formato de noticia que está subtitulado en todos los registros con subtítulos por debajo de los 15 CPS que establece la norma UNE es el background.

- En el resto de formatos de noticia, se dan los siguientes porcentajes:

Tabla 5. Resumen de las velocidades de lectura de los subtítulos en semidirecto por formatos

\begin{tabular}{|c|c|c|}
\hline Formato de noticia & $\begin{array}{c}\text { Porcentaje de subtítulos por debajo } \\
\text { de } 10 \mathrm{CPS}\end{array}$ & $\begin{array}{c}\text { Porcentaje de subtítulos por encima } \\
\text { de } 17 \mathrm{CPS}\end{array}$ \\
\hline Breves & $21,74 \%$ & $60,87 \%$ \\
\hline Cola & $6,25 \%$ & $62,5 \%$ \\
\hline Encuesta & $25 \%$ & $75 \%$ \\
\hline Pieza & $12,24 \%$ & $67,35 \%$ \\
\hline Sumario & $13,1 \%$ & $49,18 \%$ \\
\hline
\end{tabular}

En todos ellos se observa un margen de mejora considerable, porque aproximadamente las dos terceras partes de los subtítulos en semidirecto, para los cuatro primeros formatos, exceden los valores de velocidades de lecturas recomendadas. Únicamente, en el caso del sumario, dicho margen estaría presente en aproximadamente la mitad de los subtítulos.

\subsection{Análisis fílmico}

En este apartado se han examinado las dos últimas columnas del análisis fílmico, correspondientes a la «sincronía» y al «análisis de la información», que ofrecen información interesante sobre el respeto de la intersección de códigos, así como sobre la relevancia y la procedencia de la información.

\subsubsection{Sincronía}

En el modelo de análisis, se propone examinar si existe sincronía entre la imagen y la intervención indicando «Sí̀ o «No» en la pestaña correspondiente. Los resultados que se observan en la hoja de cálculo son los siguientes:

- Sincronía: valor de «Sí» en 113 registros, de los cuales 56 son de subtítulos en semidirecto y 57 de subtítulos en directo.

- Sincronía: valor de «No» en 120 registros, de los cuales 111 son de subtítulos en semidirecto y solo 9 de subtítulos en directo. 
Este resultado llama la atención, pues parece que la sincronía es mayor en los fragmentos con subtítulos en directo que en los fragmentos con subtítulos en semidirecto. En cierto modo, estos valores pueden tener sentido, puesto que, según la configuración audiovisual habitual, en las emisiones en directo suele haber imágenes reales de lo que se cuenta, mientras que en el caso de los subtítulos en semidirecto probablemente se trate de planos complementarios o que no se correspondan exactamente con el relato de los hechos.

\subsubsection{Análisis de la información}

En el modelo de análisis, se propone estudiar si la información de la pieza se ofrece por duplicado (enfoque reiterativo) o si los distintos elementos de la obra audiovisual se complementan (enfoque complementario). Los resultados que se observan en la hoja de cálculo son los siguientes:

- Análisis de la información: valor de «Reiterativo» en 195 de los 237 registros, de los cuales 142 corresponden a subtítulos en semidirecto y 53 a subtítulos en directo.

- Análisis de la información: valor de «Complementario» en 42 de los 237 registros, de los cuales 26 corresponden a subtítulos en semidirecto y 16 a subtítulos en directo.

De nuevo, estos resultados sorprenden, ya que se observa una predilección por el enfoque «Reiterativo» $\mathrm{y}$, a su vez, este se materializa con mucha más frecuencia en el caso de los subtítulos en semidirecto. Asimismo, de esta idea se podría deducir que las intervenciones son complementarias a las imágenes; es decir, que no se necesitan unas para entender las otras.

\section{Conclusiones}

En estas páginas se ha presentado un análisis descriptivo con un doble enfoque, traductológico y fílmico, sobre la SPS en directo y semidirecto de los informativos televisivos españoles. Se han analizado, desde el punto de vista traductológico, las velocidades de lectura expresadas en CPS reflejadas en un corpus representativo de once fragmentos de distintos informativos procedentes de tres canales diferentes. Desde el punto de vista fílmico, se ha comprobado que es más frecuente que las imágenes y el audio sean reiterativos, pero no necesariamente sincrónicos. De esta observación, se deduce que los informativos constituyen un tipo de producto audiovisual ya de por sí bastante accesible. De hecho, esta concepción del telediario tiene su lógica, al tratarse de un producto audiovisual pensado para que sea posible su consumo con la atención dividida, mientras se realizan otras tareas diarias y no necesariamente prestando atención plena frente a la pantalla.

Esto no quiere decir que su accesibilidad no ofrezca aún margen de mejora, como se aprecia en el análisis traductológico. Por ahora, se ha podido validar la hipótesis 
de que existe un mayor retraso entre el inicio de las intervenciones y los subtítulos que las reproducen en los subtítulos en directo que en los emitidos en semidirecto. Del mismo modo, se ha detectado una mayor velocidad de lectura en los subtítulos emitidos en semidirecto que en los subtítulos en directo. En futuras investigaciones, y con objeto de integrar aún más si cabe el análisis fílmico en la validación de las dos hipótesis planteadas, consideramos interesante comprobar si existe algún factor (parte de la pieza, técnica narrativa, movimiento de cámara, elemento de puntuación, etc.) que genere mayor o menor diferencia de tiempo entre el subtítulo y la intervención o una velocidad de lectura mayor.

Estas conclusiones han supuesto el punto de partida para el diseño y la realización de un posterior estudio de recepción que nos permita validar o refutar los resultados encontrados. Utilizando un cuestionario como herramienta de evaluación, los participantes en el experimento -usuarios con distintos tipos de sordera- han reaccionado ante una selección representativa de los fragmentos de informativos que conforman el corpus de trabajo. Para ello, se ha recurrido a piezas en los que tanto el retraso como la velocidad de lectura presentaban valores claramente diferentes. Como hemos avanzado, próximamente se publicarán los resultados de este estudio de recepción, que ofrecen datos empíricos sobre la influencia de estos dos parámetros en la comprensión de la SPS, además de la valoración general que hacen los usuarios de la accesibilidad en los informativos. A partir de estos trabajos, en el marco del proyecto ITACA se pretende, entre otros objetivos, proponer mejoras técnicas o de procesos en la SPS emitida en directo y semidirecto de los telediarios actuales.

\section{Bibliografía}

- AENOR (2012). Norma UNE: 153010. Subtitulado para personas sordas y personas con discapacidad auditiva. Madrid: AENOR.

- Casado Ruiz, Antonio (2011). La realización de programas informativos de televisión. En Periodismo en televisión. Nuevos horizontes, nuevas tendencias. Andreu Casero Ripollés y Javier Marzal Felici (eds.), 104-121. Zamora: Comunicación Social.

- Comisión Nacional de los Mercados y la Competencia (CNMC) (2019). Informe sobre el seguimiento de las obligaciones impuestas en materia de accesibilidad correspondiente al año 2017. INF/DTSA/083/18 [en línea]. 30 de enero. <https:// www.cnmc.es/sites/default/files/2311204_8.pdf $>$ [Consulta: 15 enero 2020].

- González-Iglesias González, J. David (2012). Desarrollo de una herramienta de análisis de los parámetros técnicos de los subtítulos y estudio diacrónico de series estadounidenses de televisión en DVD. Tesis doctoral, Universidad de Salamanca.

- Gutiérrez Lanza, Camino (2007). Traducción inglés-español y censura de textos cinematográficos: Definición, construcción y análisis del Corpus 0/Catálogo TRACEci (1951-1981). En Traducción y censura en España (1939-1985). Estudios so- 
bre corpus TRACE: Cine, narrativa, teatro. Merino, Raquel (ed.), 197-240. Bilbao: Universidad del País Vasco.

- Díaz Arias, Rafael (2011). Vectores del infoentretenimiento en los noticieros de televisión. En Periodismo en televisión. Nuevos horizontes, nuevas tendencias. Andreu Casero Ripollés y Javier Marzal Felici (eds.), 61-83. Zamora: Comunicación Social.

- Díaz Cintas, Jorge y Remael, Aline (2007). Audiovisual Translation: Subtitling. (Translation Practices Explained). Manchester: St. Jerome Publishing.

- Díaz Cintas, Jorge; Orero, Pilar y Remael, Aline (eds.) (2007). Media for All: Subtitling for the Deaf, Audio Description, and Sign Language. Ámsterdam: Rodopi.

- Díaz-Cintas, Jorge (2010). La accesibilidad a los medios de comunicación audiovisual a través del subtitulado y de la audiodescripción. En El español, lengua de traducción para la cooperación y el diálogo. Luis González y Pollux Hernúñez (eds.). Instituto Cervantes.

- Ivarsson, Jan y Carroll, Mary (1998). Subtitling. Simrishamn: TransEdit HB.

- Marín, Carles (2017). El informativo de televisión. Gedisa: Barcelona.

- Martí Ferriol, José Luis (2019). El proceso de pautado, la sincronización y la velocidad de lectura. En La traducción para la subtitulación en España. Mapa de convenciones. Gloria Torralba Miralles, Ana Tamayo Masero, Laura Mejías-Climent, Juan José Martínez Sierra, José Luis Martí Ferriol, Ximo Granell, Julio de los Reyes Lozano, Irene de Higes Andino, Frederic Chaume y Beatriz Cerezo Merchán (eds.), 135-146. Castellón: Publicacions de la Universitat Jaume I.

- Matamala, Anna y Orero, Pilar (2008). L'accessibilitat a TVC. Quaderns, 16, 301-312.

- Matamala, Anna y Orero, Pilar (eds.) (2010). Listening to subtitles: subtitles for the deaf and hard of hearing. Berna: Peter Lang.

- Neves, Josèlia (2008). 10 fallacies about Subtitling for the d/Deaf and the hard of hearing. The Journal of Specialised Translation, 10, 128-143.

- Neves, Josèlia (2018). Subtitling for the deaf and hard of hearing audiences. En The Routledge Handbook of Audiovisual Translation. Luis Pérez-González (ed.), 82-95. Londres: Routledge.

- Orero, Pilar; Pereira, Ana María y Utray, Francisco (2007). Visión histórica de la accesibilidad en los medios en España». TRANS. Revista de Traductología, 11, 32-43.

- Romero-Fresco, Pablo (2009). More haste less speed: edited and verbatim respoken subtitles. Vigo International Journal of Applied Linguistics (VIAL) 6, 109-133. $<$ http://vialjournal.webs.uvigo.es/pdf/Vial-2009-Article6.pdf $>$ [Consulta: 15 enero 2020].

- Romero-Fresco, Pablo (2011). Subtitling through speech recognition: Respeaking. Ámsterdam: Routledge.

- Romero-Fresco, Pablo (2013). Accessible filmmaking: Joining the dots between audiovisual translation, accessibility and filmmaking. The Journal of Specialised 
Translation 20, 201-223. <http://www.jostrans.org/issue20/art_romero.php> [Consulta: 15 enero 2020].

- Romero-Fresco, Pablo (ed.) (2015). The Reception of subtitles for the deaf and hard of hearing in Europe. Berna: Peter Lang.

- Romero-Fresco, Pablo (2018). Respeaking. Subtitling through speech recognition. En The Routledge Handbook of Audiovisual Translation. Luis Pérez-González (ed.), 96-113. Londres: Routledge.

- Romero-Fresco, Pablo y Martínez, Juan (2015). Accuracy Rate in Live Subtitling - the NER Model. En Audiovisual Translation in a Global Context. Baños Piñero, Rocío y Díaz Cintas, Jorge (eds.), 28-50. Londres: Palgrave Macmillan.

- Tamayo, Ana (2015). Estudio descriptivo y experimental de la traducción en TV para niños sordos. Una propuesta alternativa. Tesis doctoral, Universitat Jaume I.

- Zárate, Soledad y Eliahoo, Joseph (2014). Word recognition and content comprehension of subtitles for television by deaf children. The Journal of Specialised Translation 21, 133-152. <http://www.jostrans.org/issue21/art_zarate.php> [Consulta: 15 enero 2020].

\subsection{Recursos electrónicos consultados}

- ITACA. $<$ http://www.itaca.uji.es/> [Consulta: 15 enero 2020].

\section{Notas}

1. Esta investigación se enmarca en el proyecto de investigación ITACA. Inclusión social, Traducción Audiovisual y Comunicación Audiovisual, ref. FFI2016-76054-P, financiado por el Ministerio de Economía y Competitividad de España (Programa Estatal de Fomento de la Investigación Científica y Técnica de Excelencia) durante el periodo 2016-2019. Página web del proyecto: <http://www.itaca.uji.es/> [Consulta: 15 enero 2020].

2. Herramienta informática diseñada por González-Iglesias González en su tesis (2012) para el cálculo de velocidades de lectura. Accesible en línea desde <https://sourceforge.net/projects/usalblackbox/> [Consulta: 15 enero 2020]. 